Parada Bello, M. J. (enero-abril, 2022). Consideraciones políticas y pedagógicas acerca de una educación (ficcional) de los jóvenes en Colombia. Revista Virtual Universidad Católica del Norte, (65), 235-262. https://www.doi.org/10.35575/rvucn.n65a9

\title{
Consideraciones políticas y pedagógicas acerca de una educación (ficcional) de los jóvenes en Colombia ${ }^{1}$
}

Political and pedagogical considerations about a (fictional) education of Colombian youth

\section{Michael Jonathan Parada Bello}

Estudiante de Doctorado en Sentidos, Teorías y Prácticas de la Educación

Facultad de Educación, Universidad de Antioquia

Medellín, Colombia

michael.parada@udea.edu.co

Orcid: https://orcid.org/0000-0002-0778-3146

CvLAC:

https://scienti.minciencias.gov.co/cvlac/visualizador/generarCurriculoCv.do?cod_rh=0001370321

Recibido: 17 de marzo de 2021

Evaluado: 2 de agosto de 2021

Aprobado: 11 de noviembre de 2021

Tipo de artículo: Investigación Científica y Tecnológica

\section{Resumen}

La presente investigación partió de algunas afirmaciones que se hacen en relación con los jóvenes en Colombia y con lo que significaría su posible educación. Así, fue posible ver que algunos trabajos entienden la oferta educativa para los jóvenes al servicio del trabajo; o consideran que la juventud es, por definición, dependiente e incapaz y, por tanto, objeto de intervención; o asumen la educación de jóvenes como una relación que admite, simultáneamente, múltiples matices. Se trató de pensar, pues, una alternativa a los lugares así asignados para resignificar no solo los

\footnotetext{
${ }^{1}$ El presente artículo es una derivación de la tesis doctoral, dirigida por el Dr. Germán Prósperi y titulada "Ficciones de educación. Escenas literarias para pensar una educación de los jóvenes", que se adelanta en el Doctorado en Sentidos, Teorías y Prácticas de la Educación, en la Universidad Nacional del Litoral (Argentina). Agradezco los definitivos aportes del profesor Marlon Espinosa Muñoz.
} 
términos en que son referidos los jóvenes en Colombia, sino también para otorgar a la educación una dimensión de invención, en el sentido filosófico de alcanzar una palabra propia. Para lograr lo anterior, se propuso un modo singular de lectura — clínica - que permitió explorar los diferentes trabajos aquí expuestos y los por-venir; y para advertir que, en ocasiones, lo que se ofrece como efecto - no como intención - de ciertas formas de entender la educación es precisamente un empuje que lleva a la juventud hacia los bordes. Se concluyó que no poder comprender algunos aspectos de la juventud y su educación, no tiene por qué significar renunciar a pensarlas.

Palabras claves: Educación; Experiencia de borde; Ficción; Investigación; Juventud; Política.

\begin{abstract}
This research started from some statements made in relation to young people in Colombia and what their possible education would mean. Thus, it was possible to see that some jobs understand the educational offer for young people at the service of work; or they consider that youth is, by definition, dependent, and incapable and, therefore, the object of intervention; or they assume the education of young people as a relationship that admits, simultaneously, multiple nuances. Therefore, an alternative to the places assigned in this way was tried to re-signify not only the terms in which young people are referred in Colombia, but also to give education a dimension of invention, in the philosophical sense of reaching a word of its own. To achieve this, a singular mode of reading was proposed - clinical - that allowed us to explore the different works exhibited here and those to come; and to warn that, at times, what is offered as an effect — not an intention - of certain ways of understanding education is precisely a push that takes youth to the edges. It was concluded that not being able to understand some aspects of youth and their education does not have to mean giving up thinking about them.
\end{abstract}

Keywords: Education; Experience at the brink; Fiction; Research; Youth; Police. 
Para no desvelarme, voy tomando notas en ese volver a pensar, en ese dar vueltas sobre la repetición con sed de diferencia (...) Hay un proceso de investigación freudiano que puede ser emulado. En los escritos y en la práctica de Freud, todo está en revisión. Los escritos no son las

Tablas de la Ley, sino un work in progress, un borrador de un escrito futuro. No lo lastima retractarse. Más bien lo enriquece. Esto lo podemos aprender. Esto es filiación simbólica

(Hornstein, 2013, p. 14)

Creo haberle contestado [a Jean Hyppolite] poco más o menos lo siguiente: «Si viese claramente, y por anticipado, a dónde voy, creo realmente que no daría un paso más para llegar allí». Quizás pensé entonces que saber a dónde se va puede indudablemente ayudar a orientarse en el pensamiento, pero no ha hecho jamás dar un paso, todo lo contrario. ¿Para qué ir adonde se sabe que se va y adonde se sabe uno destinado a llegar? Al recordar hoy esta respuesta, no estoy seguro de comprenderla bien, pero seguramente no quería decir que nunca veo a dónde voy ni que no lo sé, y que, en consecuencia, en esa medida, en la medida en que sé, no es seguro que haya dado jamás un paso, o que haya dicho algo

(Derrida, 1997, p. 13)

\section{Introducción}

Volver a pensar, repetición con ansia de diferencia, todo en revisión, borradores, enriquecimiento en retractarse, filiación simbólica, no dar un paso en investigación si se pudiera ver claramente y por anticipado; son estas ideas que dicen algo acerca de lo que se ha podido comprender y asumir acerca del oficio de investigar. Derrida (1997) no dice que nunca ve a dónde va a llegar: dice que si lo supiera de antemano preferiría no ir en esa dirección, puesto que saber por anticipado impide caminar y decir. Cierto extravío entonces, una posición ante el no saber, admitir estar en falta de saber, investigar.

Se dirá con rodeos: la preocupación presente desde hace cierto tiempo, y que anima a pensar la presente investigación, es la educación de los jóvenes en Colombia; algunos sentidos, teorías y prácticas que puede adquirir una educación de los jóvenes. Y decimos esto porque, como se verá, se ha publicado en el país una serie de trabajos que, por lo general, tratan a la juventud 
desde una perspectiva que, cuando habla de su educación, asume la idea de "investigación en juventud" o de "estudios sobre jóvenes", o en "hacer de la juventud un objeto de estudio", lo cual implica referencias ocasionales y de soslayo a algún aspecto relacionado con su educación, y que expresan, a su vez, posiciones teóricas y prácticas con implicaciones concretas en las formas como se concibe a los adultos, a los jóvenes y, eventualmente, como se asume o hipotetiza acerca de su educación.

Se quiere, pues, pensar — derivadas de unos posicionamientos teóricos y metodológicosunas consideraciones que pongan en el centro mismo de la investigación $-\mathrm{y}$, en consecuencia, no tangencialmente - una educación — ficcional— de los jóvenes.

\section{Un posicionamiento teórico: de cómo la política de la ficción vuelve pensable una educación de los jóvenes}

Los conceptos que todavía no tienen definición son probablemente los que más expectativas de futuro ofrecen (Rilke, 1989, p. 35)

Dicho lo anterior, es posible plantear de entrada una aclaración que, a su vez, es el fundamento del posicionamiento teórico: lo que se entiende por política no se refiere - al menos inicialmente - a procesos de democratización, de participación o de formación ciudadana (Vargas, 2011), ni como fortalecimiento de "competencias ciudadanas" (Romero et al., 2017), ni tampoco a eventuales relaciones de poder (Cano Isaza y Arroyave Álvarez, 2014).

Dice Jacques Rancière (2011) que "la especificidad histórica de la literatura (...) depende de una nueva forma por la que el lenguaje actúa dando a ver y a escuchar" (p. 20). La literatura en este sentido es, pues, una cierta forma de intervenir en el reparto de lo sensible; se trata de "la manera en que el mundo se nos hace visible y en que eso visible se deja decir" (Rancière, 2011, p. 20). Para Rancière (2014b), la política se refiere, precisamente, a "lo que vemos y a lo que podemos decir, a quien tiene la competencia para ver y la cualidad para decir, a las propiedades de los espacios y a los posibles del tiempo" (p. 20). Esta forma particular de entender la política permite hacernos unas preguntas: ¿quién tiene la competencia para ver y la cualidad para decir?, ¿quién 
pone a disposición los tiempos y los espacios?, ¿a quién le pertenece ese mundo que se puede ver y sobre el que se puede decir?

Aunque pueda parecer incómoda y antipática la respuesta, se puede decir que la competencia para ver y para decir la tiene cualquiera; que el mundo no pertenece a nadie en particular, y, con ello, se inaugura el mundo común. La política en general, y la política de la literatura en particular, es la política de la experiencia común.

El problema es que "el dato sobre el que se apoya la política es siempre litigioso" (Rancière, 2011, p. 16), y si se puede decir con contundencia que cualquiera puede ver, decir o hablar, se tiene un impasse al contestar la segunda pregunta: ¿quién pone a disposición los tiempos y los espacios?, ¿quién está dispuesto al reparto de lo sensible?

Un reparto de lo sensible fija al mismo tiempo algo común repartido y ciertas partes exclusivas. Esta repartición de las partes y de los lugares se basa en un reparto de espacios, de tiempos y de formas de actividad que determina la forma misma en la que un común se presta a la participación y donde unos y otros son parte de ese reparto. (Rancière, 2014b, p. 19)

La política, se insiste, es el establecimiento de lo común. Ello implica: repartir-compartir, cierta exclusividad (cada uno retoma fragmentos por su cuenta, y se trata de no inquietarse por el no control de aquello que el otro retoma), actividad (trabajo), participación de lo común y en lo común, y, se resalta, formar parte, tomar parte y hacer tomar parte. Sin embargo, ese "punto litigioso" hace que Rancière (2014b) no sea ingenuo: "pero otra forma de reparto precede a esta forma de tener parte: aquel que determina a aquellos que son parte" (p. 19). ¿Quién determina a los que son parte?, ¿desde qué criterios?, ¿quién se encarga de los que no son parte?

La política de la literatura — que en este caso será también un modo de entender la educación de los jóvenes- consistirá entonces en intervenir en los sujetos cualesquiera y los objetos que conforman el mundo común, y en los poderes que tienen estos sujetos para verlo, nombrarlo y actuar sobre él. ¿Cómo se actúa a partir de la literatura? Pues bien, las interpretaciones son cambios reales "cuando alteran las formas de visibilidad de un mundo común y, con ellas, las capacidades que los cuerpos ordinarios pueden ejercitar sobre un nuevo paisaje de lo común" (Rancière, 2011, p. 54). Cuerpos ordinarios, cualquiera: no importa quién. La literatura y su 
política puede ser entendida, entonces, como "la capacidad que no importa quién tiene de apropiarse de no importa qué frases, palabras o historias" (Rancière, 2011, p. 41).

\section{No condenar al origen: cuando los que son nada se vuelven todo}

Para Rancière (2019) las aventuras ficcionales modernas son aquellas por las cuales "la palabra se hace carne y desvían vidas de sus destinos" (p. 17). Es por medio de estas aventuras de la ficción que se puede emprender una investigación que revele "la revolución mediante la cual los que son nada se vuelven todo" (p. 17). Dice Rancière (2019): "una investigación así puede contribuir de manera útil a ensanchar el horizonte de las miradas y de los pensamientos sobre lo que llamamos mundo y sobre las maneras de habitarlo" (p. 15). El presente trabajo suscribe plenamente esta forma de entender no solo la ficción, sino también, y fundamentalmente, la investigación ${ }^{2}$.

Se tiene entonces que la posible emergencia de lo nuevo en las ficciones modernas depende de varios factores: del momento cualquiera, de la no separación (mutilación) de las vidas, de la mezcla de temporalidades, de momentos en que una vida cualquiera se condensa. La literatura, así entendida, se consolida en ficciones que tratan lo humano, aboliendo las barreras entre la racionalidad ficcional de las intrigas y la sucesión empírica de los hechos, en cuanto que son invenciones, creaciones, de los humanos. Pero hay algo más: se trata de las vidas. El material de que están hechas las ficciones parte y alcanza vidas concretas, poco importa si de la "realidad" o la "ficción": las afecta, las toca, las elabora, las elucida. Y lo hace desde los bordes, las márgenes,

\footnotetext{
${ }^{2}$ Más que determinar un tipo de investigación, la propuesta se acerca a un posicionamiento filosófico para investigar. Así, para Arthur Schopenhauer (2013) la más alta exigencia para un investigador no es la "experticia" metodológica o ciertas formas de erudición, sino la "valentía filosófica" que consiste en "interrogarse a sí mismo implacablemente" (p. 129). Esto significa que ante una investigación — prosigue el filósofo alemán — no se pueda descansar, no pueda nadie "darse por satisfecho". Desde esta perspectiva, la "honradez intelectual" consiste, entonces, en la célebre búsqueda de la verdad -inconclusa así, pues precisamente ante ella no podemos darnos por satisfechos-. Pero para Schopenhauer (2013) la verdad no se encuentra precisamente por "el simple hecho de que no se la busca, sino que en lugar de eso se tiene la intención de redescubrir alguna opinión preconcebida o, al menos, se pretende a toda costa no dañar alguna idea predilecta; pero para ese fin hay que servirse de subterfugios de cara a uno mismo y a los demás" (p. 128). En consecuencia, cualquier investigación, por sofisticada que sea incluso en su formulación, puede ser eclipsada por preconcebidas ideas que se quisieran afirmar a toda costa $-\mathrm{y}$ que, por tanto, engañan, haciendo pasar lo sabido por lo encontrado- Se tiene pues que toda investigación aloja una implicación del investigador, una posición ante lo hallado - $\mathrm{y}$ en la que, por lo mismo, no se puede ser neutral—: verificar si se deja confrontar implacablemente por aquello que encuentra, o si prefiere no dañar lo que ya sabe y así privilegia.
} 
las fronteras, los umbrales, los intersticios, los pasajes, las bisagras, que son siempre dobles: apartan y unen, ligan y diferencian, acogen y separan:

Son en principio los bordes en los que la ficción acoge el mundo de los seres y de las situaciones que antes estaban en sus márgenes: los acontecimientos insignificantes de la existencia cotidiana o la brutalidad de una realidad que no se deja incluir. (Rancière, 2019, p. 15)

Por medio de acontecimientos insignificantes de personas cualesquiera, en momentos cualesquiera, la política de la literatura logra desviar vidas de sus destinos. Desde nuestra perspectiva, puede pensarse la educación, igualmente, como el trabajo político denodado de no condenar las vidas a los destinos que les han sido vaticinados unilateralmente.

\section{Un modo de relacionar: la política de las ficciones}

Los bordados me gustaban porque podía inventar nuevas puntadas y nuevas formas de realización

(Reyes, 2015, p. 152)

La política de las ficciones, hasta ahora, indica unas vidas que se reúnen, no fragmentadas: en los seres comunes y corrientes se presentan los sentimientos más intensos y complejos y las situaciones insignificantes que elevan a la dignidad del todo a los que no eran nada.

La democracia ficcional, la revolución democrática de la ficción es, pues,

El proceso por el cual aquellos que no eran nada se vuelven todo. Sin embargo, volverse todo, en el orden ficcional, no es volverse el personaje principal de la historia. Es volverse el tejido mismo en el seno del cual — por cuyas mallas — los acontecimientos se sostienen unos a otros. (Rancière, 2019, p. 132)

Rancière (2019) afirma que la "gran revolución que Auerbach señala sin identificar tiene lugar cuando el tejido por el cual los acontecimientos se sostienen unos a otros es el mismo por el cual suceden acontecimientos a quienes no les debería suceder nada" (p. 133). Así pues, Rancière (2019) indica que "el momento cualquiera, en realidad, no es cualquiera" (p. 134). Este puede producirse a cada instante por cualquier circunstancia insignificante. Sin embargo, 
Es también el momento siempre decisivo, el momento de transición que se aferra sobre la exacta frontera entre la nada y el todo (...) Pararse en esa frontera en la que las vidas van a oscilar entre la nada que se eleva a una totalidad de tiempo e injusticia es quizá la política más profunda de la literatura. (Rancière, 2019, p. 134)

Dichas así, estas ideas remiten a una suerte de inscripción y pertenencia, pero también de extranjería y de alejamiento que hace a la experiencia de existir. Formar parte de una manera concreta de humanidad supone la filiación en unas fronteras, que, simultáneamente, invitan a su desaparición: no en todas partes se está en casa, lo que no necesariamente quiere decir desprotegido.

Al respecto, Jean-Pierre Vernant (2008) asegura que:

Cruzar un puente, traspasar un río, atravesar una frontera, es abandonar el espacio íntimo y familiar donde uno está en su sitio para penetrar un horizonte diferente, un espacio extranjero, desconocido, donde se corre el riesgo, al confrontarse con el otro, de descubrirse sin lugar propio, sin identidad (...) Para que haya verdaderamente interior, es preciso que éste se abra hacia el exterior para recibirlo en su seno (...) Para ser uno mismo, es preciso proyectarse hacia lo que es extranjero, prolongarse en y por él. Permanecer encerrado en su identidad es perderse y dejar de ser (...) Entre las riberas de lo mismo y de lo otro, el hombre es un puente. (pp. 178-179)

El fragmento anterior invita a bordar y desbordar los bordes, las fronteras, atravesarlas. ¿A riesgo de qué? De perderse y dejar de ser, desviar las vidas de sus destinos, para realizarlas de otros modos, para hallar, inventar nuevas puntadas.

\section{Metodología. Una lectura clínica}

Si en la selección uno sigue sus expectativas, corre el riesgo de no hallar nunca más de lo que ya sabe;

y si se entrega a sus propias inclinaciones, con toda seguridad falseará la percepción posible

(Freud, 1912/1979, p. 112) 


\section{Consideraciones políticas | Revista Virtual \\ Universidad Católica del Norte, 65, 235-262 \\ ISSN: 0124-5821 (En línea)}

Todo lo anterior solicita, ya, presentar los trabajos que en Colombia dicen algo acerca de la juventud y de lo que ocasionalmente se expresa allí acerca de la “educación” de los jóvenes. Antes de esto, sin embargo, es necesario hacer una aclaración. Según el escritor portugués Gonçalo Tavares (2016), cuando uno se enfrenta a un problema, la pregunta no es tanto “¿qué herramientas necesito?” (p. 124) como “¿qué herramientas tengo que aprender a utilizar?” (p. 124). Asumir tal posición exige, entonces, una desviación respecto de los consabidos caminos de infinitas repeticiones $-\mathrm{y}$, por ello, infértiles ${ }^{3}$ - a propósito de las inscripciones metodológicas en la investigación. Esa sería una respuesta a la pregunta por las herramientas que se necesitan — para repetirlas —, mas no por aquellas que se tienen que aprender — para elaborarlas—.

Así, este trabajo de investigación exige casi como principio ocuparse de explicitar una perspectiva de la lectura. Con este propósito, se ha logrado asociar algunos pensamientos que, estando diseminados en principio, fueron apareciendo inadvertidamente para formar un tejido que sólo ahora se puede enlazar.

Para el psicoanalista Juan Fernando Pérez (1997), la lectura intratextual ${ }^{4}$, además de ser lo que denomina un tiempo de lectura "indispensable e ineludible" (p. 112), es un principio intelectual y metodológico para lo que él considera un "bien leer” (p. 112). ¿De qué se trata? Metodológico porque implica un modo singular de acercarse a "un texto cualquiera" (Pérez 1997, p. 113), e intelectual porque supone una "manera de interrogar en el lector su tendencia espontánea a la autoafirmación en sus posiciones, fundamentales o triviales" (Pérez, 1997, p. 113). Este "acto de discusión" (Pérez, 1997, p. 112) que se propone entre el texto y el lector, deriva en lo que Pérez llama "el pensar". Se trataría, pues, de no autoafirmarse; de dejarse interrogar, de poner en suspenso "toda lectura o referencia adicional" (Pérez, 1997, p. 113); de aceptar y admitir un no saber. Así, Pérez (1997) indica que “difícilmente se podrá concebir la lectura como investigación

\footnotetext{
${ }^{3}$ Como se ha dicho desde el inicio del presente escrito, cuando se presenta una pura repetición, sin ansia de diferencia, cuando una investigación da rodeos en torno al mismo punto y no apunta a un desplazamiento, se dirige a un lugar estéril, en tanto que no consigue significaciones renovadas. Es posible indicar que es importante para el pensamiento hallar el desplazamiento en la repetición. Lo cual sugiere que no es simplemente repitiendo como se puede pensar; el pensamiento requiere — es más: exige - encontrar para "cada situación" una forma singular de inventar una respuesta. Para Jacques Rancière (2014a), por ejemplo, el pensamiento está asociado a la "capacidad de deshacer fronteras", lo cual supone también un desplazamiento en el que el trabajo del pensamiento "consista menos en demostrar como en hacer que se muevan los puntos de referencia a partir de los cuales se operan las demostraciones" (p. 117). De este modo, los conceptos designan "un operador de desplazamiento, la apertura de un campo de pensamiento" (p. 120).

${ }^{4}$ Noción que, como el mismo Pérez (1997) señala, no es completa creación suya, pero que a su vez significa "con propósitos y sentidos que no coinciden estrictamente" (p. 112) con los campos de donde aquella proviene.
} 
al asumirla como un acto de autoafirmación” (p. 119). Se subraya acá la idea de lectura como investigación.

Una cierta ingenuidad en la lectura. Elias Canetti (2012) refiere que cuando estaba escribiendo su obra Masa y poder trataba de no anteponer sus juicios a las lecturas que la escritura de dicha obra demandaba:

En cada período, es importante investigar los fenómenos más relevantes de la época con una mirada nueva, y abordarlos de manera totalmente ingenua — en la medida en que podamos abordarlos - antes de aplicarles algún tipo de concepto [...] Durante mucho tiempo intenté no desembocar en ningún concepto predeterminado. (Canetti, 2012, p. 794) La ingenuidad, enseña Canetti (2012), no estriba en el hecho de ignorar una situación determinada; se encuentra en no anteponer los (pre)juicios cuando se quiere acercar a una obra que se pretende leer. La aplicación de una teoría a una práctica no sería más que su constatación, con lo cual no solo se deja intacta la teoría — que se torna así en lenguaje de nivel superior y que remite, entonces, al totalitarismo del concepto, a una teoría totalizante-, sino que se perdería la ocasión de una mirada nиeva respecto de algo que se pretende pensar.

Por su parte, Dany Laferrière (2011), escritor haitiano, relata en su libro El arte casi perdido de no hacer nada, que un joven se le acerca y le pregunta ¿qué es un buen libro? Laferrière no da una respuesta contundente ni certera (tampoco se le exige) y no fue satisfactoria para ninguno de los dos interlocutores. Sin embargo, no es posible omitir un fragmento en el que sí define con claridad lo que sería un "mal lector": aquel que busca desembarazarse de todo lo que no se parece a lo que ya ha leído (Laferrière, 2011, p. 132).

De este modo, tres escritores, en distintos registros, permiten pensar una posición a mantener en la lectura: no autoafirmarse; esto es, no tratar de desembarazarse de lo que no se parezca a lo que ya se sabe, o se cree saber. Se trata de pensar.

Un psicoanalista, de otro tiempo y latitud, Didier Anzieu (1995), señala que pensar:

Es diferir las respuestas a las preguntas, a fin de tener tiempo de elaborarlas, evitando la precipitación y la prevención (Descartes, 1637): lo que Derrida llama la "différance" (diferancia con una a), el aplazamiento, la espera, para oponer a la diferencia (con una e), a las diferenciaciones introducidas a continuación por la toma en consideración de las categorías. (pp. 16-17) 
Dilatar. Se dilata para no apresurarse, para no anteponer, para no prevenirse. Tampoco se trata de pasársela en diferido. Pero sí de no afanarse, darse el tiempo.

Antes bien: un escritor colombiano, Ricardo Silva (2017), se pregunta ¿por qué siendo tan fácil leer, es tan difícil? Se cree que da una respuesta que cierra y abre lo que hasta ahora se ha dicho en compañía:

Se pierden muchos lectores porque muchos entran a leer corrigiendo ${ }^{5}$, muchos entran a leer a la caza de defectos (...) cuesta todavía más leer el trabajo del otro tal como es y no como uno lo habría hecho o como querría que fuera (...) cuesta, mejor dicho, enfrentarse a los demás sin juzgarlos, sin corregirlos (...) Leer es, mejor dicho, leer lo que está ahí: dramatizar, poner en escena e interpretar, pero lo que está ahí, no lo que uno quiere o piensa o prefiere que esté ahí. Y es tan difícil de hacer porque requiere cederle el escenario a otro, concederle el beneficio de la duda a lo que tiene enfrente, entrar en una tregua en la guerra contra todo y contra todos, poner en pausa los prejuicios, permitirle a las palabras ajenas que se lo tomen a uno, que se dedican a despertarlo a uno órgano por órgano cuando el caos de afuera se ha vuelto el caos de adentro. (p. 100)

De este modo, entonces, se indica que esta forma de entender la lectura, y una metodología que no fueran mera repetición, supone una suerte de desposesión de un saber que quisiera siempre capturar de manera infalible y anticipable los "hallazgos" de una investigación. Esta manera de entender anima y orienta una forma de curiosidad contrapuesta al descontento que puede provocar lo ya sabido. No se trata, entonces, de leer para corregir, o para perseguir y alcanzar la norma ideal que caracterizaría la educación de los jóvenes, o su definición última. Se trata de pensar, en los términos referidos, lo que los textos permiten conocer en lo desconocido, admitiendo también que quedará algo definitivamente incognoscible.

Así pues, los "resultados" que a continuación se presentan devinieron de una lectura así entendida, lo que sugiere que no estaban trazados de antemano. Temporalmente se ha resuelto denominarlos así: 1) la oferta educativa para los jóvenes debe estar al servicio del trabajo; 2) la

\footnotetext{
${ }^{5}$ Es Derrida (2006) quien, a propósito de la imposibilidad de enseñar y de aprender a vivir, permite plantear una discusión a ciertas formas de entender la educación como lo que se podría denominar una pulsión de corregir: "Apostrofar a alguien para decirle $<<\mathrm{Te}$ voy a enseñar a vivir $\gg$, significa, a veces en tono de amenaza, voy a formarte, incluso voy a enderezarte" (p. 21).
} 
juventud es, por definición, dependiente e incapaz y, por tanto, objeto de intervención; o 3) la educación de jóvenes es una relación que admite, a su vez, múltiples matices.

\section{Resultados. Encuentros provisionales, momentáneos, parciales y fragmentarios}

Hay una juventud que (...) se pregunta, cuando llega al borde del mundo, qué le propone ese mundo (Badiou, 2016, p. 91)

¿Qué se propone, en términos educativos, a los jóvenes en Colombia? Esta preocupación, aunada a lo encontrado en algunos estudios acerca de la juventud y de la "educación" de los jóvenes, moviliza el pensamiento que origina las siguientes páginas. Los hallazgos presentados están divididos en tres categorías; cada una da cuenta de presupuestos y conjeturas acerca de los jóvenes y su educación en Colombia, que no dejan de acarrear, una y otra vez, consecuencias concretas en sus vidas.

\section{Una oferta educativa al servicio del trabajo}

La idea de la educación como preparación de las nuevas generaciones para el mundo laboral, como fuerza de trabajo, es un lugar común en los trabajos preocupados por la oferta educativa a los jóvenes en Colombia. Así, José Rubén Castillo (2011), en un estudio que quiere rastrear, con una perspectiva histórica, "la relación política y juventud a partir de los años sesenta del siglo XX” (p. 102) en Colombia, caracteriza lo que, para él, es la educación y la escuela:

En el capitalismo, la escuela se convierte en el espacio propicio para la aparición de los estudiantes; institución asignada en esta sociedad para preparar a las nuevas generaciones en calidad de fuerza de trabajo. Antes las personas pasaban de la familia a la actividad productiva. Con este modo de producción, se hizo necesario que las actividades de preparación de los jóvenes para el trabajo se hicieran en una institución en la cual permanecieran un tiempo determinado mientras lograban adquirir los saberes básicos que requerían para desenvolverse adecuadamente en el medio laboral. (p. 111) 
Además de que la educación sea equiparada aquí con la escuela, conviene decir que en estas formas de significar lo escolar se puede leer un sentido sociológico más o menos clásico: una escuela al servicio del capitalismo, creada para reproducir la cultura dominante y, casi como consecuencia inexorable, para producir mano de obra calificada. En este sentido, la juventud queda atrapada entre una forma de entender la oferta educativa como el camino expedito para su cualificación como trabajadores y el mundo laboral como — casi único—- destino.

Es el mismo parecer de autores como Hurtado y Simmonds (2011), quienes, al equiparar también "escolarización" con "educación", entienden la escuela como escenario de moratoria social donde "la juventud emerge como ese periodo o tiempo en el cual a las jóvenes y a los jóvenes se les prepara para luego insertarse en el mundo adulto o mundo del trabajo" (p. 136). Se vuelve, pues, a la misma idea analizada anteriormente, lo cual no puede más que suscitar algunas preguntas: ¿Es posible pensar - reducir- la educación solo en el registro del progreso, la profesión y el trabajo? ¿Se puede instituir la escuela, y en general la educación, de otros modos para la juventud? ¿Qué sucede cuando el mundo adulto es solo el mundo del trabajo? ¿Qué acaece cuando la oferta educativa se circunscribe exclusivamente a lo laboral?

En el mismo sentido ya presentado, Hurtado y Simmonds (2011) aseguran que, en el siglo XX, los jóvenes "se formaban para luego ser insertados" (p. 137) al sistema productivo de su clase. En este contexto, indican los autores en mención,

La escuela se convierte en el escenario del disciplinamiento y de la formación de ese sujeto trabajador, pero como lapso de tiempo; y [...] es el espacio en el cual a esos jóvenes escolares se les dispensa de asumir responsabilidades sociales, económicas y laborales. (pp. 137-138)

Esta forma de significar la educación juvenil también da a pensar si detrás de considerarla como una moratoria social, en la que se suspenden diversas responsabilidades y como un disciplinamiento, no hay una hipótesis del otro como peligroso, amenazante, alguien en quien no se puede confiar y que, en tal sentido, hay que cuidarse de él. ¿Qué consecuencias tendría para una educación de los jóvenes la hipótesis descrita?

Se puede establecer, así, una relación entre las formas de concebir la educación -sentidos, y sus promesas y efectos en las vidas concretas de jóvenes a la vez concretos. Esto supone que hablar de "educación de jóvenes" implica explicitar el o los sentidos que esa educación adquiere; 
las marcas que lleva; los efectos que procura y no solo una definición de la juventud, bien como clase de edad o como "cultura juvenil".

\section{Una juventud dependiente e incapaz; por tanto, objeto de intervención}

Otro de los imaginarios dominantes sobre la educación de los jóvenes en Colombia es el de una juventud irresponsable y sin autonomía, razón por la cual habría que convertirla en objeto de intervención. De esta manera, y con el interés de pensar a los jóvenes en su condición de estudiantes universitarios, Napoleón Murcia (2008) señala que la universidad es un escenario "académico orientado hacia la formación para el desempeño de una profesión" (p. 823). El autor asegura que en el imaginario de lo que él llama "moratoria social", atribuido a la vida universitaria, "se instituye una función central de la Universidad: la formación profesional, en medio de la cual incluso el estudiante construye un imaginario de dependencia e incapacidad" (Murcia, 2008, p. 823). Así, Murcia (2008) afirma que los estudiantes comentan, en talleres y relatos de historias de vida, "que su principal objetivo en la universidad es terminar una carrera para poder ejercer bien la profesión" (p. 838).

Más allá de que se comparta —o no— esta idea de universidad, conviene puntualizar una idea: ¿de qué o de dónde se deriva el "imaginario" estudiantil de "dependencia e incapacidad"? ¿Cuáles son las condiciones institucionales para que ello acaezca? ¿Qué elementos, factores, decisiones, posiciones de profesores universitarios (educadores, en particular) animan o contrarrestan estos efectos?

De otro lado, para Murcia (2008) ser joven universitario:

Antes que exaltación y reconocimiento autónomo es desconocimiento de capacidades, en el marco de un modelo que asume la condición juvenil como adolescencia e incapacidad. Así, el joven universitario vive una doble marginalidad: por un lado, la marginalidad propia del modelo de moratoria que los condena a aplazar su potencial hasta «llegar a ser», de acuerdo con el plan que el adulto les ha trazado; y por otro, la marginalidad de los estudios culturales y comprensivos que al considerarlos incluidos - a los jóvenes-, no los ven como sujetos clave de comprensión en los procesos de investigación. (p. 830) 
La hipótesis que el autor presenta es crucial: los jóvenes "llegan a ser" del mismo modo en que el plan de los adultos les ha trazado. Así las cosas, surge las preguntas: ¿es esta una forma de ser "educador" ante otros, y específicamente ante los jóvenes? ¿Qué implicaciones tendría esta forma de ser educador? ¿Se pueden aventurar fundaciones nuevas en las formas de presencia de los educadores ante la juventud? Pero, además, el autor sostiene que, en el ámbito universitario, se desconocen las "capacidades" del joven, se lo considera un sujeto incapaz y marginado, que todavía "no es". Estas hipótesis acerca de los jóvenes y de la universidad, ¿a qué idea de educación responden o qué idea de educación implican? ¿Qué efectos sobre los jóvenes puede provocar una educación -bien sea universitaria, escolar u otra- que los desconozca, margine, reduzca, aminorice?

Después de hacer un largo despliegue de la historia de los movimientos estudiantiles y su relación con la constitución de la Universidad de Manizales específicamente, Murcia (2008) asegura que los jóvenes universitarios no siempre han tenido, en esa universidad en particular, el estatuto de "estudiantes", pero que una vez lograda dicha designación es posible advertir que "ha sido construida desde dinámicas muy disímiles que muestran una ebullición de sentidos y significados que terminan por reconocer al estudiante únicamente como «objeto» de la intervención de todos los procesos de la universidad" (Murcia, 2008, p. 836). Parece mostrar el autor una nueva forma, aunque implícita, de una propuesta educativa universitaria: reconocer al estudiante únicamente en tanto objeto de intervención. En clave educativa es posible preguntarse: ¿qué posibilidades acarrea para un joven ser únicamente objeto de intervención educativa? ¿Qué dice acerca de la educación esta pasividad con que se describe al joven? ¿Qué dice acerca del joven esta idea de educación? ¿Qué función desempeña esta idea de joven en una educación así formulada? ¿Se puede pensar el lugar del joven en la educación de otros modos?, ¿cuáles?, ¿Qué se asegura una educación cuando reserva al joven el lugar de objeto pasivo de la relación?

Por otra parte, el autor caracteriza la relación de profesores y estudiantes universitarios de una llamativa manera. Asegura que "la mayoría de los profesores ven en sus estudiantes personas con grandes problemas de responsabilidad y desinterés; personas a quienes poco les interesa la vida de la universidad y a veces tampoco los procesos que en ella se desarrollan" (Murcia, 2008, p. 837). Murcia (2008) endilga lo anterior a lo que considera constituye el imaginario de la "moratoria social" que, según él, "desfigura la responsabilidad y con ello la calidad de la educación, en tanto formación de capacidades relacionadas con la autonomía y la responsabilidad" 
(p. 841). Aquí la educación, considerada fundamentalmente una formación para la autonomía y la responsabilidad, es embestida, según el autor, por la "moratoria social" en un sentido muy específico: la moratoria "como imaginario central, manipula el concepto de formación, estructurándola como simbólico de aplazamiento, de expectativas puestas en espera, de compensar una deficiencia, de tener siempre un maestro o una maestra como punto de referencia" (Murcia, 2008, p. 842). Para Murcia (2008) las relaciones entre adultos y jóvenes muestran

La discriminación social y el menosprecio hacia el adolescente; un menosprecio paternalista y proteccionista, pues por depender del adulto no tiene ninguna autonomía social, cultural o ético-política, toda vez que las decisiones sobre su vida y su futuro dependen de lo que le tengan preparado; es el adulto quien no solamente programa su vida, sino que la controla. (p. 841)

La moratoria social — que, como se ve, es una hipótesis traída y propuesta por el autortiene una función definida: manipular la formación; entorpecer la responsabilidad y la autonomía de los jóvenes. Y, además, otorga un lugar muy particular a los maestros: ser siempre puntos de referencia para los jóvenes. Algunas preguntas no se hacen esperar: ¿tener un tiempo de formación implica la manipulación de esta última? ¿Qué sucede cuando un maestro -educador en generalquiere ser siempre punto de referencia para los estudiantes? ¿Qué idea de educación subyace al postulado de eternidad, dependencia y manipulación de los educadores sobre los jóvenes? ¿La dependencia produce - tiene que producir - solo tal invalidación del otro? ¿Es — tiene que serel adulto, educador, un programador y controlador de la vida del joven? ¿Se puede ser adulto educador - sin el afán de controlar y programar? ¿Se puede serlo para aplastar la vida? ¿O puede la educación, por el contrario, hacer vivir la vida, instituyéndola?

\section{La educación de los jóvenes como relación}

En una línea de sentido que se ha venido presenciando, esto es, lo que algunos trabajos han denominado la moratoria social, algunos autores como Alejandro Muñoz y Luis García (2011) aseguran que existe una relación entre moratoria social y educación, y presentan una idea de las instituciones educativas como lugares de construcción identitaria de los jóvenes: 
La institución educativa juega un papel preponderante en la construcción de identidad por parte del sujeto joven, con sus pretensiones de producir un sujeto funcional (entre otras). Así las cosas, el joven o la joven requiere de instrucción o capacitación. (Muñoz y García, 2011, p. 149).

Por lo anterior, aseguran los autores, la escuela es:

El espacio propicio para el estudio de las dinámicas conflictivas en las adscripciones identitarias del contexto educativo. En este espacio, las interacciones entre jóvenes, y entre jóvenes y personas adultas visibilizan con más intensidad la coexistencia del entramado de tensiones que emergen como producto de las interacciones sociales y las demandas adultocéntricas. (Muñoz y García, 2011, p. 150)

La relación intergeneracional es reconocida como fuente de tensiones. Los autores afirman que las interacciones sociales y las demandas centradas en el adulto producen una intensidad particular. Para efectos de lo que este trabajo quiere pensar se pueden plantear algunas preguntas: ¿Se presentan ofertas identitarias en el espacio escolar? ¿De dónde provienen? ¿De qué tipo son? ¿Qué sucede cuando el escenario escolar no oferta oportunidades de adscripciones identitarias? ¿Las demandas educativas son exclusivamente adultocéntricas? ¿Es posible pensar el lugar adulto, en tanto educador, únicamente como uno de demanda?

Así, los autores señalan una forma de significación del adulto en una relación -educativacon el joven: "los discursos juveniles también implican un imaginario simbólico que significa al sujeto adulto, llámese padre, madre o persona encargada, como el depositario de la regulación de la actuación del sujeto joven" (Muñoz y García, 2011, p. 155). El papel que los discursos juveniles reservan a los adultos comporta, según Muñoz y García, un carácter exclusivamente regulador. Esto sugiere unas preguntas más: ¿Qué sucede cuando el educador oficia solo como regulador de los jóvenes? ¿Qué acontece con la oferta identitaria y sus posibles adscripciones si el educador hace presencia solo en un lugar de regulador? ¿Qué permite y deniega la regulación? ¿Es posible una educación que no sostenga regulaciones? ¿Es posible una que no disponga fuentes identitarias? Y, sin embargo, aquí se podría aventurar un giro de tuerca: ¿y si la idea de que los discursos juveniles reservan a los adultos un carácter exclusivamente regulador no corresponde tanto a dichos discursos como a la ficción que los adultos crean de sí mismos en el imaginario de los jóvenes? 
En este orden de ideas, habría que pensar, primero, si esa es la imagen que en efecto se tiene (y, sobre todo, si es la única que se puede tener) del joven en el ámbito universitario; y, segundo, si el maestro, allí, es (y puede ser) solo una suerte de "policía" que controla, vigila, regula, o si pueden pensarse otras formas de presencia de los profesores universitarios, en otro tipo de relaciones que digan de una institución que pase, a su vez, por entender de otras maneras los vínculos educativos que se puedan gestar en la universidad.

Finalmente, Muñoz y García (2011) aseguran que el adultocentrismo es “considerado como la hegemonía de la interpretación del mundo desde la postura del sujeto adulto/masculino/occidental" (p. 155) y que

Opera como un dispositivo de control social que establece las mismas relaciones de dominio centro-periferia, y que permite la ilusión de un modelo evolutivo en el desarrollo psicológico de los sujetos, en donde los jóvenes y las jóvenes aparecen como en tránsito a la adultez y, por lo tanto, como sujetos que "están siendo" "sin ser"; o una moratoria social en la cual el sujeto es des-responsabilizado y ubicado en el escenario del ocio "privilegiado" en la condición del "no futuro". (Muñoz y García, 2011, p. 155)

Esta manera en que son caracterizadas las formas de presencia de los adultos ante los jóvenes permite, al menos, preguntas como: ¿Son estos modos los únicos posibles de relación educativa- entre jóvenes y adultos? ¿Qué consecuencias ofrece para unas prácticas que se pretendan educativas el hecho de considerar a los que se dirigen como alguien que no es? ¿Qué consecuencias ofrece para unas prácticas que se pretendan educativas el hecho de considerar a los que se dirigen como unos cuya condición es el no futuro? ¿Para qué una educación que quisiera liberarse del futuro de sus destinatarios?

Esta línea de pensamiento muestra que algunos autores no ignoran la idea de educación como relación. Así pues, en el intento de comprender los significados que un grupo de jóvenes universitarios les atribuyen a las relaciones adulto-joven y a "lo público", Victoria Pinilla y Germán Muñoz (2008) hacen referencias a lo que los jóvenes sienten o se representan en relación con el lugar que tienen para los adultos. Con todo, es necesario indicar que la relación adulto-joven que aquí se asume se enmarca en una perspectiva en que la relación con lo educativo es tangencial. Sin embargo, ofrece elementos para pensar lo que podría constituir una educación de los jóvenes, en términos de relaciones intergeneracionales. 
Pinilla y Muñoz (2008) encuentran, pues, que en los relatos de jóvenes que participaron de la investigación subsiste un reclamo:

Por el señalamiento al que se sienten expuestos por algunos sectores de la sociedad, como consecuencia de la representación negativa que se tiene de ellos, explícita en las reacciones discriminatorias asociadas a su condición de jóvenes (imposición de estereotipos). Son vistos como exóticos, diferentes, peligrosos, un grupo fuera de control al que hay que someter. (p. 788)

De este modo, aseguran los autores, la relación que estos jóvenes describen con los adultos está marcada por una desconfianza:

En lo social y en lo político, los universitarios también se sienten relegados a la periferia al detectar relaciones asimétricas con las personas adultas, y al sentirse ignorados, cuando no se les reconoce como interlocutores válidos. Hablan, pero no se sienten escuchados, porque las personas adultas no se toman la molestia de considerar lo que ellos dicen, los dejan hablar, pero no se les tiene en cuenta; hay quienes piensan que más bien se da cierto aprovechamiento por parte de las personas adultas. (Pinilla y Muñoz, 2008, p. 789)

Como se dijo, si bien es cierto no se habla explícitamente de educación, sí es posible advertir algunos postulados que permiten pensar vínculos entre jóvenes y adultos, postulados que no dejan de tener relación con cierta forma de entender la educación. Lo interesante a pensar —al menos desde esta perspectiva - es por qué la presencia de asimetría en la relación se constituye para los jóvenes en una sensación de ser ignorados, desconocidos y anónimos a los ojos de los adultos. ¿La asimetría puede entrar a justificar formas del desconocimiento, el desprecio, el anonimato, la indiferencia? ¿Puede ser entendida y puesta en práctica de otros modos? ¿Es la asimetría desigualdad?

Además, aseguran Pinilla y Muñoz (2008) que:

Desde esta disyunción, ambas generaciones están limitadas por sus propios referentes; están manejando una lógica social fragmentadora de los vínculos, que rompe los puentes de comunicación entre jóvenes y personas adultas, debilita las posibilidades de encuentro con los otros, fomenta la indiferencia y hace a las personas menos inclinadas a asumir responsabilidades sociales. En las dos generaciones, parece ser que los meta-discursos lo instituido socialmente-, es usado como referencia para la acción de los adultos, 
mientras que los micro-discursos — la preocupación por lo cotidiano-, orientan la actuación de los jóvenes". (p. 794)

Lo anterior tiene una implicación ética "importante", según los autores: "es el no reconocimiento, por parte de las dos generaciones, del otro como interlocutor, generador de discurso, argumentador, sujeto de palabra y acción" (Pinilla y Muñoz, 2008, p. 794). Asuntos que salen a la vista, como la indiferencia, la desconfianza, la falta de reconocimiento, son elementos para considerar en el marco de una apuesta por pensar sentidos, teorías y prácticas que fundamenten los vínculos educativos que se pueden establecer entre adultos y jóvenes.

Es posible ver, pues, como el objeto de esta investigación atraviesa y está atravesado por disputas teóricas, prejuicios, posiciones, metodologías y concepciones que implican sentidos y prácticas otorgados explícita o implícitamente a la educación de los jóvenes. Lo anterior, no quiere decir que no se puedan desentrañar dichos sentidos, analizar sus fundamentos, ni que no se puedan interrogar, interpelar ni discutir, con el ánimo, sobre todo, de considerar alternativas, proponer otros caminos, alentar nuevas conceptualizaciones que tuvieran, quizás, otros alcances prácticos y otorgaran otros sentidos a la educación de los jóvenes en Colombia.

\section{Discusión: una problematización a propósito de la educación de los jóvenes en Colombia}

Querría rogarle lo mejor que sepa (...) que intente amar las preguntas mismas. No busque ahora las respuestas, que no se le pueden dar, porque usted no podría vivirlas. Viva usted ahora las preguntas.

Quizá luego, poco a poco, sin darse cuenta, vivirá un día lejano entrando en la respuesta (Rilke, 1980, p. 47)

Como se dijo en el epígrafe del apartado anterior, Badiou (2016) parece sugerir que si no existen propuestas de mundo - oficio que, desde cierta perspectiva, corresponde a los que ya están: grandes, adultos, viejos — lo que queda como oferta para ciertos — ¿muchos? — jóvenes es llegar al borde. Ahora, también habría que examinar qué sucede cuando, como lo vimos en el anterior apartado, las ofertas que se presentan a los jóvenes pasan por una educación para el 
trabajo; o una en la que son considerados nadie; o una en la que parecen envidiados por tener un tiempo - "moratoria social"- en el que son exonerados de ciertas responsabilidades. En consecuencia, habría que explorar cuáles son los sentidos que los jóvenes otorgan a estas ofertas. Lo anterior, para pensar si la "llegada a los bordes" por parte de ciertos jóvenes — ¿muchos? tal vez tenga relación - y cuál es - con las ofertas recibidas, los sentidos, los sinsentidos o las faltas de sentido que puedan hallar en dichas ofertas.

A diferencia de los estudios presentados, esta investigación trata, entonces, de pensar lo que es posible denominar como las condiciones institucionales de un trabajo educativo, que se pueda legar, transmitir, pasar, para que —quizá- los jóvenes no lleguen al borde. O para que el borde no sea lo único que se registre como oferta o como inexorable efecto de la oferta. Perspectivas estas que, se puede conjeturar, develan mucho más del adulto $-\mathrm{y}$ del mundo que presentan y ofrecen - que de la juventud a nombre de la que hablan los estudios expuestos en el apartado inmediatamente anterior.

Así pues, se trata de emprender un camino investigativo en Colombia que se ocupe y pueda ofrecer elementos para pensar sentidos, teorías y prácticas que permitan fundamentar una educación de los jóvenes que sostengan, a modo de algunas implicaciones prácticas, al menos las que siguen: no dejarlos atrapados en los bordes; que, por el contrario, les presente ofertas diversas; les habilite la tentación; les prometa aperturas de mundo en que no queden excluidas la curiosidad, ni la sorpresa, ni el asombro; que aísle toda pretensión de privilegio y abra oportunidades para todos. Es decir, que haga del borde el comienzo de un espacio así.

Conviene, entonces, pensar por qué los jóvenes, por alguna razón, se van de la escuela o de la universidad, o son excluidos de formas de relación que los protejan, o son desterrados de maneras de instituir en ellos y con ellos la vida, lo vivo de la vida. Que es ya una forma de discutir la idea de la educación en su equiparación-reducción al escenario escolar. Desde luego, este análisis no puede ser contemplativo, y precisa considerar, nuevamente, el lugar de los adultos: sus posiciones, exabruptos, aciertos, consideraciones, vacilaciones, equívocos, apuestas, ofertas, silencios, injusticias; advertir, también, una vez más, el lugar de los jóvenes: sus señalamientos, oposiciones, seguridades, temores, sueños, anhelos, provocaciones, ideas, apasionamientos; y, sin duda, elucidar otra vez las relaciones entre unos y otros: sus singularidades, motores, silenciamientos, ambivalencias, intensidades, matices. 
Todo esto con un riesgo a sostener: el de una invención teórica -ficcional- que seguramente solicitará múltiples disciplinas que permitan configurar -o renovar- sentidos a su vez múltiples de la educación de los jóvenes. Se trata, en últimas, de la ocasión de emprender una búsqueda, una exploración, que permita romper las fronteras disciplinarias, superar las fragmentaciones teóricas y articular los diferentes registros.

En este orden de ideas, se puede hablar de una necesidad antropológica de la ficción que se funda en lo que se denomina dos gestos antropológicos, quizá entreverados: por una parte, porque hay ficción en la medida en que se inventan y se reinventan las propias definiciones, que no pueden ser nunca definitivas. En tal sentido, el primer gesto antropológico de las ficciones es el de conmover aquello que no se puede ser mientras se siga siendo lo mismo. Ya se ha tenido la oportunidad de reseñar la importancia que tiene, desde esta perspectiva, poder atravesar los puentes que llevan de un lugar a otro para no ser siempre los mismos; para conjurar la mera repetición.

En segundo lugar, porque las ficciones se fundan en la imposibilidad antropológica de un todo saber, lo cual invita a la ficción. Se anota que dicha imposibilidad acarrea, a su vez, dos "frentes": un no saber todo el saber "epistémico", pero también un no saber todo el saber acerca de sí mismo (subjetivo). En la medida en que se pueda bosquejar que el ser humano es inaccesible a sí mismo, borroso para sí mismo, se puede aseverar que, en consecuencia, en los límites del saber emerge la ficción como aquello que permite conocer, pero, sobre todo, reinventar lo conocido.

Es posible de este modo reconocer, entonces, que la ficción no se presenta como una trivial oposición con la realidad, sino que opera con esta para ponerla a decir otra cosa que, sin embargo, no se sabe a priori. Así es que el fondo de la cuestión antropológica de las ficciones es que hacen surgir algo que "no existe todavía" (Iser, 1997, p. 52), para lo cual se precisa sostener que en lo humano hay "algo que no se puede ser mientras se siga siendo lo mismo" (Iser, 1997, p. 52).

Lo anterior supone una suerte de desposesión de un saber acerca de lo educativo que quisiera siempre capturar de manera infalible y anticipable "la realidad", y arroja, más bien, a la "penumbra de posibilidades" (Iser, 1997, p. 59). Dicho así, se puede afirmar que no hay mentira en la ficción; que las ficciones no son mentira, sino que "van más allá de lo que hay, incluso aunque no puedan existir sin lo que hay. Son aquellas que dependen de lo que hay, pero que no pueden derivarse de lo ya existente" (Iser, 1997, p. 59). Y como no aparece el atrincheramiento en lo ya existente que acapara ciertas formas del conformismo, se puede decir que es en la penumbra de lo 
por inventar que subsiste la posibilidad de bosquejar realizaciones siempre imprevisibles, que se apartan precisamente de un saber que se pretendiera a sí mismo seguro e infalible.

Si lo anterior tiene alguna posibilidad de verdad, se puede decir que hay cosas que no se saben y que, por tanto, se tienen que inventar. Conviene indicar que existe algo así como un doble apuntalamiento de la ficción: por una parte, descubre - hace de-velar - aspectos del mundo, de "la realidad", que se desconocían, pero que permiten elaborar otras formas; y, por otro, permiten tramitar de algún modo — nunca terminante ni clausurado - el no saber.

Llegados a este punto, es posible puntuar que la ficcionalización resulta ser una forma de valorar "la mutabilidad históricamente condicionada de deseos humanos guardados en lo más profundo" (Iser, 1997, p. 62), a condición de admitir que nunca se revelarán ni podrán tramitarse de modo completo. Así entendida, la ficción es una suerte de prótesis, de artificio necesario, que pone a dar rodeos sobre unos modos de existencia de los que no se tienen -ni se pueden tenertestimonio de manera directa. Las ficciones permiten así "una asociación ilimitada de realidades que llevan el sello de la impenetrabilidad cognitiva" (Iser, 1997, p. 62). Dicha ilimitación no es, ciertamente, infinita, sino posible en el sentido de realizable por la ficción, pero que encuentra, como se dijo, el límite de lo incognoscible.

Ya se ha indicado que no es posible saber todo el saber "epistémico" - como contracara se ha dicho que se pueden conquistar saberes fragmentarios, parciales y provisionales-. Pero tampoco es posible saber todo el saber subjetivo. Así pues, "las fronteras del conocimiento" activan la ficcionalización (Iser, 1997, p. 62), incluso acerca de nosotros mismos. Anota Iser (1997) que:

Hay realidades de la vida humana que experimentamos, pero que, a pesar de todo, no podemos conocer (...) Sabemos que hay cosas que existen, pero también sabemos que no podemos conocerlas [del todo], este es el punto ante el que despierta nuestra curiosidad, y por eso empezamos a inventar. (p. 62)

El recurso a la curiosidad reclama una asociación de ruptura con lo ya existente. Esto último puede hacer presencia incluso a modo de prejuicio. Un cierto modo de habilitar las ficciones vuelve disponible, entonces, una posibilidad de sorpresa.

Se encuentran profundas resonancias con estos postulados porque, como se puede advertir, ello se vincula íntimamente con las ideas de que todo saber es fragmentario, provisional, 
parcialmente elaborado, elaborable y reelaborable, que ya se ha desarrollado en apartados anteriores y que tiene una presencia definitiva para esta investigación.

De este modo, no se trata, respecto de los trabajos que dan fundamento a este estudio - y que se han tratado en el apartado anterior-, de adquirir un saber faltante ni de afirmar la voz propia de los autores de dichos trabajos ni la de quienes esto escriben. Como pudo verse, no es que falte saber, no es que haya un déficit de saber; se trata, en cambio, de aventurar fundaciones nuevas. En este sentido, la posición que se sostiene en esta investigación es la de despojarse de cierto saber y de cierta voz. ¿Para qué? Para lograr una "palabra propia". Y en el pensamiento de Rancière (2019), para conquistar dicha palabra es preciso desidentificarse del orden dado. Es posible decir, por tanto, que emprender este trabajo requiere, precisamente, desidentificarse de lo que los autores sostienen en relación con los jóvenes y su posible educación; exige desmarcar a los jóvenes y a los adultos de los lugares así asignados, e invita a designar unos sentidos -otros- a una educación posible destinada a la juventud. En otras palabras, elucidar "otra razón en el mismo argumento" (Rancière, 1996, p. 9); es decir, ahí donde se afirma que la educación de los jóvenes debe estar al servicio del trabajo, o se considera que la juventud es, por definición, dependiente e incapaz y, por tanto, solo objeto de intervención, se puede intentar no solo otras formas de relación entre generaciones, sino también unas perspectivas teóricas que amplíen los modos mismos de entender la educación, especialmente la destinada a los jóvenes en Colombia.

\section{A modo de conclusión}

Se emprendió una búsqueda de los márgenes desde los cuales vislumbrar senderos distintos a los acostumbrados. Es así como, desconociendo de antemano los destinos de tales búsquedas, se intentó ensanchar el campo de lo pensable en torno a la educación de los jóvenes a partir de los movimientos que la política de la ficción permite. Como se vió, en trabajos recientes de Rancière se considera la política como la operación de desviar vidas de sus destinos y, también, como el reparto de lo sensible. Así, se asume la idea de una política que vuelva pensables otras formas de entender la educación de los jóvenes. De manera oblicua estas ideas acarrean unas implicaciones, en palabras y actos, vinculadas a la educación de los jóvenes y sus vidas. 
Es posible advertir hasta aquí varias puntualizaciones que, quizá, hablen de unas irrupciones y, subrepticia pero simultáneamente, de juventud: se puede ver el carácter de renovación, interrupción, desconcierto, enigma, incertidumbre, asombro, sorpresa, extranjería, fisura, marginalidad, advenimiento, partida, fuga, borde, desborde, extraterritorialidad, que se adjudica a las irrupciones. Con todo, no se pierde de vista que son los jóvenes y sus escenas las que autorizan a hablar de irrupciones de la juventud; estas son logradas como efecto de lectura, no como categorización anticipada. De pronto se tenga que recurrir a otra idea, renunciando, eso sí, a la explicación.

Pensar, pues, la potencia del concepto de irrupción para la juventud implica sostenerse en la extrañeza y los intersticios. El presente trabajo requiere, entonces, trastocar la noción misma de "propia voz", y relacionarlo, más bien, con lo extraño, lo extranjero. La irrupción, finalmente, es lo inesperado que viene a desestabilizar, lo cual es uno de los rasgos de la juventud. En este caso en particular se refiere a unas indicaciones que se vinculan con formas de leer que estén atentas a lo que ingresa sin pedir permiso. Y ello no descuida la conformación de una manera de atender a lo que los jóvenes vuelven pensable en relación con su educación.

Se dice esto porque, en ciertos sentidos, alguna pedagogía niega la idea de que lo que se pone en juego en la educación es una ficción no prescriptiva. Al respecto, se puede pensar en una relación entre la educación, la formación y la literatura (que ya se ha establecido - piénsese, por ejemplo, en las denominadas novelas de formación - pero que exige renovación). De este modo, se observa una relación precisa y contundente entre diversos saberes, a propósito de la educación y la formación de los jóvenes, lo cual permitiría, quizás, interrogar, con el horizonte de renovar, una tradición pedagógica que ha encontrado en la ficción una manera de moralizar la educación.

Así las cosas, el "sin destino" identificado e identificable que provoca la expulsión a los márgenes, a los bordes, no se puede traducir a "desviar el destino" porque se conoce de antemano el contenido de dicho destino — el "cierto", el "verdadero" —. Sino dejarlo abierto a lo que no se conoce anticipadamente, a lo que no se puede significar a priori, puesto que le corresponde al otro, y que podrá realizar, en todo caso, si confiamos en que lo acometerá en un tiempo que no nos pertenece.

Para delinear este escrito, es posible decir que las irrupciones confrontan al pensamiento con la imposibilidad de comprenderlo todo: algo quedará por fuera, no se podrá significarlo, algo 
se escapará, se fugará y encontrará, tal vez, otras lecturas que lo intenten atrapar, o de pronto quedará definitivamente fugado, inaprensible. Si es cierto, finalmente, que lo que constituye a las irrupciones es que hay en ellas un resto del orden de lo incomprensible, se puede señalar, sin embargo, que no por solo parcialmente comprensibles, sean totalmente impensables.

\section{Referencias}

Anzieu, D. (1995). El pensar. Del Yo-piel al Yo-pensante. Biblioteca Nueva.

Badiou, A. (2016). Nuestro mal viene de más lejos. Capital Intelectual.

Canetti, E. (2012). Obras Completas V. La conciencia de las palabras. Galaxia Gutenberg.

Castillo, J. (2011). La configuración de las prácticas políticas en estudiantes universitarios. En G. Muñoz (Ed.), Jóvenes, culturas y poderes (pp. 101-124). Siglo del Hombre; Universidad de Manizales; Cinde.

Derrida, J. (1997). El tiempo de una tesis. Deconstrucción e implicaciones conceptuales. Proyecto a.

Derrida, J. (2006). Aprender por fin a vivir. Amorrortu.

Freud, S. (1979). Consejos al médico sobre el tratamiento psicoanalítico. En S. Freud, Obras Completas T. XII (pp. 107-119). Amorrortu. (Obra original publicada en 1912).

Hornstein, L. (2013). Las encrucijadas actuales del psicoanálisis. Subjetividad y vida cotidiana. Fondo de Cultura Económica.

Hurtado, D., y Simmonds, M. (2011). Imaginarios de juventud y ciudad en maestros y maestras de la ciudad de Popayán. En G. Muñoz (Ed.), Jóvenes, culturas y poderes (pp. 125-144). Siglo del Hombre; Universidad de Manizales; Cinde.

Cano Isaza, T. A., y Arroyave Álvarez, O. A. (2014). Procesos de empoderamiento de mujeres: subjetivación y transformaciones en las relaciones de poder. Revista Virtual Universidad $\begin{array}{llll}\text { Católica del } & \text { Norte, } & \text { 94-110. }\end{array}$ http://revistavirtual.ucn.edu.co/index.php/RevistaUCN/article/view/497/1033

Iser, W. (1997). La ficcionalización: dimensión antropológica de las ficciones literarias. En A. Garrido (Comp.), Teorías de la ficción literaria (pp. 43-65). Arco/Libros. 
Laferrière, D. (2011). L'art presque perdu de ne rien faire [El arte casi perdido de no hacer nada] [Marlon Espinosa, Trad.]. Les Éditions du Boréal.

Muñoz, D., y García, L. (2011). Adscripciones identitarias de jóvenes como horizontes de sentido de dinámicas conflictivas juveniles. En G. Muñoz (Ed.), Jóvenes, culturas y poderes (pp. 145-160). Siglo del Hombre; Universidad de Manizales; Cinde.

Murcia, N. (2008). Jóvenes universitarios y universitarias: una condición de visibilidad aparente en Colombia. Revista Latinoamericana de Ciencias Sociales, Niñez y Juventud, 6(2), 821852. http://revistaumanizales.cinde.org.co/rlcsnj/index.php/Revista-

\section{Latinoamericana/article/view/245/129}

Pérez, J. F. (1997). Elementos para una teoría de la lectura. Utopía Siglo XXI, 1(1), 111-126.

Pinilla, V., y Muñoz, G. (2008). Lo privado de lo público para jóvenes universitarios en Colombia. Revista Latinoamericana de Ciencias Sociales, Niñez y Juventud, 6(2), 769-800. https://www.redalyc.org/articulo.oa?id=77360210

Rancière, J. (1996). El desacuerdo. Filosofía y política. Nueva Visión.

Rancière, J. (2011). Política de la literatura. Libros del Zorzal.

Rancière, J. (2014a). El método de la igualdad. Conversaciones con Laurent Jeanpierre y Dork Zabunyan. Nueva Visión.

Rancière, J. (2014b). El reparto de lo sensible. Estética y política. Prometeo Libros.

Rancière, J. (2019). Los bordes de la ficción. Edhasa.

Reyes, E. (2015). Memoria por correspondencia. Edhasa.

Rilke, R. M. (1980). Cartas a un joven poeta. Alianza Editorial.

Rilke, R. M. (1989). Cartas a Benvenuta. Grijalbo.

Romero, C., Villareal, S., Samper, J., y Ospino, I. (2017). Fortalecimiento de las competencias ciudadanas a partir de la lectura crítica en escenarios virtuales. Revista Virtual Universidad $\begin{array}{llll}\text { Católica del } & \text { Norte, } & \text { 216-232. }\end{array}$ http://revistavirtual.ucn.edu.co/index.php/RevistaUCN/article/view/853/1371

Schopenhauer, A. (2013). Sobre la visión y los colores. Seguido de la correspondencia con Johann Wolfgang Goethe. Trotta.

Silva, R. (2017). Por qué es tan difícil leer. Ruta Maestra, (20), 94-100. https://bit.ly/39wcEBc

Tavares, G. (2016). Enciclopedia. Ediciones Uniandes. 


\section{Consideraciones}

políticas

Consideraciones políticas | Revista Virtual

Universidad Católica del Norte, 65, 235-262

ISSN: 0124-5821 (En línea)

Vargas, N. (2011). Formación política y ciudadana en ambientes virtuales: reflexiones a partir de una sistematización de experiencia en educación popular en la Escuela de Formación Ciudadana de la Facultad de Derecho de la Universidad Santo Tomás, Medellín. Revista Virtual Universidad Católica del Norte, (32), 56-72. https://revistavirtual.ucn.edu.co/index.php/RevistaUCN/article/view/26

Vernant, J-P. (2008). Atravesar fronteras. Entre mito y política II. Fondo de Cultura Económica. 